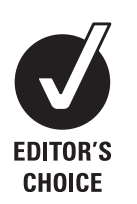

See Editorial, p 185

${ }^{1}$ Department of Primary Care $\mathcal{\&}$ Public Health, Imperial College London, London, UK

${ }^{2}$ Aragon Health Sciences Institute, Zaragoza, Spain ${ }^{3}$ National Heart and Lung Institute, Imperial College London, London, UK ${ }^{4}$ Division of Medicine, Imperial College London, London, UK 5 Intelligence, Information, Policy and Research, Care Quality Commission, London, UK

\section{Correspondence to} Dr Michael Soljak, Department of Primary Care \& Public Health, Imperial College London, 3rd Floor, Reynolds Building, Charing Cross Campus, Imperial College London, London, UK; m.soljak07@imperial.ac.uk

Received 14 July 2010 Accepted 7 October 2010 Published Online First 12 November 2010

\title{
Association of population and primary healthcare factors with hospital admission rates for chronic obstructive pulmonary disease in England: national cross-sectional study
}

\author{
Amaia Calderón-Larrañaga, ${ }^{1,2}$ Leanne Carney, ${ }^{1}$ Michael Soljak, ${ }^{1}$ Alex Bottle, ${ }^{1}$ \\ Martyn Partridge, ${ }^{3}$ Derek Bell, ${ }^{4}$ Gerrard Abi-Aad, ${ }^{5}$ Paul Aylin, ${ }^{1}$ Azeem Majeed ${ }^{1}$
}

\begin{abstract}
Background Hospital admission rates for chronic obstructive pulmonary disease (COPD) are known to be strongly associated with population factors. Primary care services may also affect admission rates, but there is little direct supporting evidence.

Objectives To determine associations between population characteristics, diagnosed and undiagnosed COPD prevalence, primary healthcare factors, and COPD admission rates primary care trust (PCT) and general practice levels in England.
\end{abstract}

Design, setting, and participants National crosssectional study $(53,676,051$ patients in 8,064 practices in 152 English PCTs), combining data on hospital admissions, populations, primary healthcare staffing, clinical practice quality and access, and prevalence. Main outcome measures Directly and indirectly standardised hospital admission rates for COPD, for PCT and practice populations.

Results Mean annual COPD admission rates per 100 000 population varied from 124.7 to 646.5 for PCTs and 0.0 to 2175.2 for practices. Admissions were strongly associated with population deprivation at both levels. In a practice-level multivariate Poisson regression, registered and undiagnosed COPD prevalence, smoking prevalence and deprivation were risk factors for admission $(p<0.001)$, while healthcare factors- influenza immunisation, patient-reported access to consultations within two days, and primary care staffing, were protective $(p<0.05)$.

Conclusion Associations of COPD admission rates with deprivation, primary healthcare access and supply highlight the need for adequate services in deprived areas. An association between admission rates and undiagnosed COPD prevalence suggests that casefinding strategies should be evaluated. Of the COPD clinical quality indicators, only influenza immunisation was associated with reduced admission rates. Patients' experience of access to primary care may also be clinically important.

\section{INTRODUCTION}

Around 210 million people have chronic obstructive pulmonary disease (COPD) worldwide. ${ }^{1}$ The WHO has estimated that there will be a $30 \%$ increase in COPD deaths in the next 10 years and that COPD will become the third leading cause of death by $2030 .^{2}$ The natural history of COPD involves gradual deterioration in lung function, marked by exacerbations requiring primary care intervention or hospital admission, a gradual decline in quality of life and reduced life expectancy. ${ }^{3}$

The total annual cost of COPD to the English National Health Service (NHS) is over $£ 800$ million (US\$1215 million), and it has become the second largest cause of emergency hospital admissions in the UK. ${ }^{4}$ The Department of Health $(\mathrm{DH})$ for England has released a COPD national strategy ${ }^{5}$ and it also has a range of policies to improve longterm condition management in primary care, with the aim of improving quality and length of life and reducing hospital admissions. For example, it has introduced a 'pay for performance' programme, the Quality and Outcomes Framework (QOF), which rewards general practices for identifying (by registering on practice computer systems) and managing effectively (by achieving a number of evidence-based quality indicators) a number of long-term conditions, including COPD. As a result, national data are available on registered prevalence and indicator achievement for almost all practices. ${ }^{6}$ Over three quarters of a million people are on general practice COPD registers in England, but a mathematical prevalence model estimates that the actual number with the disease is about 1.2 million. $^{7}$

Reducing unnecessary hospital admissions will play a critical role in ensuring the NHS and other health systems meet the challenge of real terms reductions in resources-the 2010 UK Budget report factors in potential savings of $£ 2.4$ billion from this source. ${ }^{8}$ COPD is one of a number of ambulatory or primary care sensitive (PCS) conditions, for which it is hypothesised that risk of hospital admission will be reduced by effective primary care management. ${ }^{9-11}$ However, PCS conditions have mainly been identified by expert opinion rather than empirically. ${ }^{12} 13$ Previous research has also been hampered by lack of detailed data about practice populations and the quality of primary care services, such as is now available through QOF, or has been carried out only at primary care trust (PCT) level (PCTs are NHS organisations responsible for groupings of practices in geographic areas). ${ }^{14-17}$

Some population factors-especially deprivationare strongly associated with PCS condition admission rates, and there are weaker associations with primary care access and supply factors. Effective management of COPD may reduce the risk of 
hospital admission. Godtfredsen et al found a gradient of RR of hospital admission with increasing smoking prevalence. ${ }^{18}$ In addition, combination treatment with long-acting beta-agonists and inhaled corticosteroids reduces the annual rate of COPD exacerbations and improves health status and spirometric values. ${ }^{19} 20$ A systematic review demonstrated that patients with COPD who received interventions with two or more components of the Chronic Care Model had lower rates of hospitalisations. ${ }^{21}$

The aim of this study was to examine the associations between population characteristics, including both diagnosed and undiagnosed prevalence, primary healthcare factors, and COPD admission rates at PCT and practice levels in England. Both levels of analysis are desirable, as aggregation to PCT level could mask important associations present at practice level. Specific objectives were first to investigate the associations between rates of hospital admission for COPD and population factors (deprivation, smoking prevalence, QOF registered/diagnosed prevalence rates and undiagnosed, ie, expected minus $\mathrm{QOF}$ registered prevalence rates). The second objective was to investigate associations between admission rates and a range of healthcare factors, after adjustment for population factors. These included access factors (general practitioner (GP) and practice nurse supply and QOF access indicators), COPD-specific QOF quality indicators, and smoking cessation advice or referral, to explore their relative impacts. As all UK residents are entitled to primary care consultations which are free at the point of use, and as the vast majority of residents are registered with a practice, there are no apparent barriers to access. However, despite NHS resources being allocated on a needs-weighted population basis, there are quite wide variations in access as measured by patients' experience of the availability of unscheduled care and appointments-hence the inclusion of these indicators in QOF.

\section{METHODS}

\section{Hospital episodes statistics data}

NHS-funded hospitals in England are responsible for providing data to the Hospital Episodes Statistics (HES) database. A hospital episode forms all or part of an overall hospital spell (one complete admission). We used hospital spells for this analysis to avoid multi-counting. Admissions were selected where the primary diagnosis, that is, main reason for admission met International Classification of Diseases version 10 J44.0-44.9 (other COPD, excluding asthma and other nonCOPD) for all patients 15 years of age and over admitted during financial years 2006-2007, 2007-2008, 2008-2009 to maximise the number of admissions per practice. It was not possible to validate the HES diagnosis against data from practice COPD registers as only aggregate QOF data are available.

\section{QOF data}

QOF includes standardised information on the quality of care provided by 8229 general practices in 152 English PCTs. We used QOF data from the Health and Social Care Information Centre website for April 2008-March 2009. ${ }^{6}$ OOF indicators are split between four quality domains (clinical, organisational, patient experience and additional services). The QOF clinical domain included 129 evidence-based indicators of the clinical quality of care including five indicators for COPD (table 1). We used the number of COPD patients recorded by general practices (registered prevalence), the total list sizes of patients per practice as denominators (the definition used by the Information Centre), the total QOF points achieved for the COPD domain and individual indicators for specific COPD care (ie, spirometric confirmation of diagnosis, recent record of forced expiratory volume in one second $\left(\mathrm{FEV}_{1}\right)$, inhaler technique and influenza immunisation offered). Since stopping smoking affects the prognosis of COPD, we also included the percentage of patients with a chronic disease whose notes record that smoking cessation advice or referral to a specialist service has been offered within the previous 15 months (Smoking 4). To measure broad access to care from the patient perspective we used two new patient experience (PE) indicators introduced in the 2008-2009 QOF, which were derived from the results of the national GP Patient Survey, and which measure ability to access a GP consultation within 2 days (PE7), and ability to book an appointment with a GP more than 2 days ahead (PE8).

\section{Practice staffing}

The Health and Social Care Information Centre provided data on GP and nurse supply (GPs and practice nurses per 100000 population), at practice and PCT levels, respectively, as of September $2007 .{ }^{22}$ Practice nurse numbers do not include other nurses working in the community, such as 'community matrons' or district nurses, who may have contact with COPD patients.

\section{Undiagnosed prevalence data}

We used practice-level predictions of COPD prevalence from the Association of Public Health Observatories website, which uses a model developed by Nacul et al ${ }^{7}$ This uses spirometry data from the 2001 Health Survey for England to produce prevalence estimates for population subgroups. It uses the British Thoracic Society definition of COPD, that is, $\mathrm{FEV}_{1}$ divided by forced vital capacity (FVC) under 0.70 , and $\mathrm{FEV}_{1}$ less than $80 \%$ of predicted, a more stringent definition than the National Strategy. The model includes practice-level values of age, sex (population data as of March 2007), ethnicity, deprivation, smoking and urbanisation to estimate overall COPD prevalence, and has been validated against estimates from population surveys. Practiceregistered COPD prevalence was then subtracted to estimate undiagnosed prevalence. Further information about the COPD model development is provided on the Association of Public Health Observatories website. ${ }^{23}$

\section{Population data}

The Care Quality Commission (COC) provided estimates by sex and 5 -year age band of registered patients by practice and PCT in England, as of April 2008. The Department of Communities \& Local Government Index of Multiple Deprivation (IMD) 2004 data for England were used to measure deprivation ${ }^{24}$-high scores indicate a high level of deprivation. IMD data were available for 152 PCTs. A deprivation weighting for each practice was obtained from the COC. This was produced by aggregating IMD scores from postcodes of individual patients in practice populations.

\section{Statistical analysis}

The basic unit of analysis was the general practice population. Indirect standardisation is generally accepted as more robust when counts are relatively small, so indirectly standardised admission rates were calculated at the practice level, to produce overall expected admission rates for each practice based on the England age/sex specific rates. These were compared to the observed practice-level admission numbers. Baseline PCT characteristics were then calculated including registered population (the sum of registers of general practices located within PCTs' geographic boundaries), age distribution, IMD, practices per 
Table 1 Quality and Outcomes Framework indicators for COPD management and patient experience in 2008-2009 which were analysed

\begin{tabular}{|c|c|c|}
\hline Indicator & Points & $\begin{array}{l}\text { Payment } \\
\text { thresholds }\end{array}$ \\
\hline \multicolumn{3}{|l|}{ COPD quality indicators } \\
\hline \multicolumn{3}{|l|}{ Records } \\
\hline \multicolumn{3}{|l|}{ COPD 1} \\
\hline $\begin{array}{l}\text { The practice can produce a register of } \\
\text { patients with COPD }\end{array}$ & 3 & \\
\hline \multicolumn{3}{|l|}{ Initial diagnosis } \\
\hline \multicolumn{3}{|l|}{ COPD 12} \\
\hline $\begin{array}{l}\text { The percentage of all patients with COPD } \\
\text { diagnosed after } 1 \text { April } 2008 \text { in whom the } \\
\text { diagnosis has been confirmed by post } \\
\text { bronchodilator spirometry }\end{array}$ & 5 & $40-80 \%$ \\
\hline \multicolumn{3}{|l|}{ Ongoing management } \\
\hline \multicolumn{3}{|l|}{ COPD 10} \\
\hline $\begin{array}{l}\text { The percentage of patients with COPD } \\
\text { with a record of FEV } 1 \text { in the previous } \\
15 \text { months }\end{array}$ & 7 & $40-70 \%$ \\
\hline \multicolumn{3}{|l|}{ COPD 11} \\
\hline $\begin{array}{l}\text { The percentage of patients with COPD } \\
\text { receiving inhaled treatment in whom there } \\
\text { is a record that inhaler technique has been } \\
\text { checked in the previous } 15 \text { months }\end{array}$ & 7 & $40-90 \%$ \\
\hline \multicolumn{3}{|l|}{ COPD 8} \\
\hline $\begin{array}{l}\text { The percentage of patients with COPD } \\
\text { who have had influenza immunisation in } \\
\text { the preceding } 1 \text { September to } 31 \text { March }\end{array}$ & 6 & $40-85 \%$ \\
\hline \multicolumn{3}{|l|}{ Smoking quality indicator } \\
\hline \multicolumn{3}{|l|}{ Smoking 4} \\
\hline $\begin{array}{l}\text { The percentage of patients with coronary } \\
\text { heart disease, stroke or TIA, hypertension, } \\
\text { diabetes, COPD, CKD, asthma, } \\
\text { schizophrenia, bipolar affective disorder or } \\
\text { other psychoses who smoke whose notes } \\
\text { contain a record that smoking cessation } \\
\text { advice or referral to a specialist service, } \\
\text { where available, has been offered within } \\
\text { the previous } 15 \text { months }\end{array}$ & 35 & $40-90 \%$ \\
\hline \multicolumn{3}{|l|}{ Patient experience indicators } \\
\hline \multicolumn{3}{|l|}{ PE7 Patient experience of access (1) } \\
\hline $\begin{array}{l}\text { The percentage of patients who, in the } \\
\text { appropriate national survey, indicate that } \\
\text { they were able to obtain a consultation } \\
\text { with a GP (in England) }\end{array}$ & 23.5 & $70-90 \%$ \\
\hline \multicolumn{3}{|l|}{ PE8 Patient experience of access (2) } \\
\hline $\begin{array}{l}\text { The percentage of patients who, in the } \\
\text { appropriate national survey, indicate that } \\
\text { they were able to book an appointment } \\
\text { with a GP more than } 2 \text { days ahead }\end{array}$ & 35 & $60-90 \%$ \\
\hline
\end{tabular}

*The lower and upper achievement levels required to receive the minimum and maximum payment.

CKD, chronic kidney disease; COPD, chronic obstructive pulmonary disease; GP, general practitioner; TIA, transient ischaemic attack.

PCT and practice list size. Practice level characteristics (QOF points and indicator breakdown) were aggregated to PCT level, as required. As admission counts were larger at PCT level, directly standardised (age and sex) admission rates were calculated per 100000 GP registered population, using the total England population as the standard with which to weight the PCT rates. Three-year averages of registered and estimated COPD prevalences were summarised and undiagnosed prevalence calculated.

At practice and PCT levels, bivariate associations between admission rates and the above continuous independent variables were first assessed using Spearman's correlation coefficient. For the PCT level analysis, least-squares linear multivariate regression models were then fitted to examine the effects of all independent variables. At the practice level, because of low admission numbers, we applied Poisson regression, where standard errors have been scaled using the square root of the deviance-based dispersion. The dependent variable was observed count of hospital admissions and the offset was the expected number of admissions. Poisson regression returns incidence rate ratios (IRRs), which in this context can be considered as analogous to ORs. Microsoft Excel and Access were used to manage the data and the software package Stata10 was used for all statistical analysis.

\section{RESULTS}

The 152 English PCTs had a total GP-registered population of 53547488 patients (table 2). The GP-registered population in each PCT varied from 94635 to 1294596 (mean 352 286). We were able to match all the data required for 8064 (90.3\%) GP practices from a total of 8932. List size varied from 984 to 38343 (mean 6603). Estimated smoking prevalence at practice level varied from $13.2 \%$ to $51.7 \%$. QOF scores achieved were generally high, for influenza immunisation, inhaler technique and spirometry, although there was a wider variance in PCTs recording spirometry (76.0-96.4\%) and recording $\mathrm{FEV}_{1}$ (75.5-89.3\%). The range of QOF Patient Experience scores also tended to be lower.

Table 3 summarises the observed, estimated and calculated undiagnosed prevalence levels for COPD at the PCT and practice level. The England mean prevalence of registered COPD in the whole population is $1.5 \%$ (SD $0.0 \%$ ), and undiagnosed COPD is $2.2 \%$ (SD 0.1\%). Mean (over 3 years) annual hospital admission rates for COPD per 100000 population varied from 124.7 to 646.5 (median 241.5, IOR 178.1-331.4) at PCT level and 0.0 to 2175.2 (median 179.0, IOR 111.1-288.2) at general practice level, illustrating the greater variance observable in a practice level analysis. Over $98 \%$ of admissions were in the 45 years and over age group.

\section{Regression modelling}

In the bivariate regression of exposure variables against hospital admission rates at PCT level, deprivation and smoking prevalence were the variables with highest explanatory power, accounting for $59.3 \%$ and $51.4 \%$ of the total variance, respectively $(\mathrm{p}<0.001)$. Estimated prevalence accounted for $45.1 \%$ of the variance $(\mathrm{p}<0.001)$ compared to the observed (registered) COPD prevalence $(21.9 \%, \mathrm{p}<0.001)$. About $14.4 \%$ of the variance in hospital admissions was explained by GP supply $(p<0.001)$. The QOF COPD overall clinical quality score was shown to account for only $2.1 \%$ of the variance $(p=0.034)$. Among all specific clinical QOF indicators, the score for influenza immunisation showed the highest explanatory capacity $(6.9 \%, p<0.001)$. In the multivariate regression model using reverse stepwise variable selection $\left(R^{2}=75.0 \%\right)$, the undiagnosed disease prevalence as well as all QOF clinical indicators were not retained in the model using a probability criterion of 0.1 (table 4).

Table 4 also shows the practice-level analysis using Poisson regression with reverse stepwise variable selection. The highest IRR was estimated for observed prevalence ( $I R R=1.224$, $\mathrm{p}<0.001$ ), and undiagnosed prevalence, deprivation, smoking prevalence, GP supply and access to a GP consultation, and influenza immunisation status were also retained in the final model using reverse stepwise variable selection and a probability criterion of 0.1 . Overall COPD score, and clinical quality indicators COPD 10, COPD 11, COPD 12 and Smoking 4 all dropped out of this model. 
Table 2 Characteristics of PCT and practice populations

\begin{tabular}{|c|c|c|c|c|c|c|c|c|c|}
\hline & \multirow[b]{2}{*}{ Mean } & \multicolumn{4}{|c|}{ PCT level } & \multicolumn{4}{|c|}{ Practice level } \\
\hline & & (SD) & Min-Max & Median & IOR & (SD) & Min-Max & Median & IOR \\
\hline PCT population & 352286 & 193433 & $94635-1294596$ & 292118 & $225238-422895$ & - & - & - & - \\
\hline Practice population & 6603 & - & - & - & - & 4011 & $984-38343$ & 5774 & $3394-9011$ \\
\hline Percentage of people $15-34$ years & 27.5 & 25.7 & $19.6-43.1$ & 43.1 & 25.7 & 7.8 & $10.5-98.5$ & 25.7 & $22.4-30.0$ \\
\hline Percentage of people $35-74$ years & 48.1 & 3.8 & $34.2-53.7$ & 49.3 & $45.5-50.9$ & 6.6 & $1.3-64.4$ & 49.5 & $45.3-52.5$ \\
\hline Percentage of people $75+$ years & 7.2 & 1.8 & $2.9-12.3$ & 7.2 & $6.3-8.2$ & 2.9 & $0.0-26.4$ & 7.2 & $5.3-8.9$ \\
\hline IMD (deprivation) score & 23.7 & 9.1 & $8.1-48.3$ & 23.6 & $16.1-29.8$ & 12.6 & $2.2-71.9$ & 21.3 & $13.4-32.0$ \\
\hline GPs/100000 population & 60 & 7 & $44-81$ & 59 & $55-64$ & 17 & $8-334$ & 55 & $10-180$ \\
\hline Practice nurses/100 000 population & 28 & 7 & $0-60$ & 28 & $24-32$ & - & - & - & - \\
\hline \multicolumn{10}{|l|}{ QOF clinical indicators* } \\
\hline Total COPD score & $96.2 \%$ & $2.6 \%$ & $83.7-99.9 \%$ & $96.8 \%$ & $94.8-98.2 \%$ & $9.9 \%$ & $0.0-100 \%$ & $100 \%$ & $99.4-100 \%$ \\
\hline Influenza immunisation & $91.6 \%$ & $1.2 \%$ & $86.9-95.5 \%$ & $91.8 \%$ & $90.9-92.4 \%$ & $6.3 \%$ & $0.0-100 \%$ & $92.7 \%$ & $89.5-96.1 \%$ \\
\hline $\begin{array}{l}\text { Smoking cessation advice or referral } \\
\text { to a specialist service }\end{array}$ & $92.7 \%$ & $1.1 \%$ & $89.2-95.3 \%$ & $92.9 \%$ & $92.1-93.5 \%$ & $5.3 \%$ & $26.6-100 \%$ & $93.1 \%$ & $91.1-95.8 \%$ \\
\hline \multicolumn{10}{|l|}{ QOF patient care experience indicators* } \\
\hline $\begin{array}{l}\text { Ability to obtain a consultation within } \\
\text { two working days }\end{array}$ & $84.8 \%$ & $8.4 \%$ & $0.0-92.8 \%$ & $85.6 \%$ & $82.9-88.3 \%$ & $14.1 \%$ & $0.0-100 \%$ & $87.3 \%$ & $79.3-93.0 \%$ \\
\hline $\begin{array}{l}\text { Ability to book an appointment with } \\
\text { a GP more than } 2 \text { days ahead }\end{array}$ & $77.3 \%$ & $8.4 \%$ & $0.0-89.0 \%$ & $77.8 \%$ & $75.2-81.0 \%$ & $17.6 \%$ & $0.0-100 \%$ & $80.8 \%$ & $67.3-90.3 \%$ \\
\hline
\end{tabular}

*Total points/available \%.

COPD, chronic obstructive pulmonary disease; GP, general practitioner; IMD, Index of Multiple Deprivation; PCT, primary care trust; Q0F, Quality and Outcomes Framework.

\section{DISCUSSION}

In this cross-sectional study of hospital admissions for COPD, registered COPD prevalence, undiagnosed prevalence, smoking prevalence and deprivation were all risk factors for hospital admission $(p<0.001)$. Primary healthcare factors such as being offered influenza immunisation, patient-reported access to primary care consultations within 2 days, and primary care supply (GPs and practice nurses per 100000 population) were protective factors $(p<0.05)$. There was an overall consistency in the findings at organisation and practice levels, but with additional independent variables being retained in the practice level model and with stronger associations apparent. At practice level, after adjustment for deprivation, undiagnosed COPD prevalence as well as diagnosed disease was strongly associated with the rate of hospital admission. Primary healthcare factors such as being offered influenza immunisation, patient-reported good access to GP consultation, and GP and practice nurse supply were also significantly associated with reduced hospital admission rates.
Hospital admissions for COPD were strongly associated with deprivation scores and smoking prevalence at both PCT and practice level. This relationship has been documented previously, ${ }^{25} 26$ but associations with primary care supply less often. Saxena et al studied the association at London PCT level between population and practice factors with hospital admission rates for PCS conditions (including COPD). ${ }^{17}$ They found some associations between primary healthcare factors and admission rates, but not with practice resourcing. By contrast, a practice level analysis of hospital admissions for asthma in East London found that practice characteristics were the strongest predictor of the admission rate, but the most likely explanation for this result could be that the geographically small region under investigation was uniformly deprived. ${ }^{16}$ In our study, GP supply was inversely associated with hospital admission rates at the practice (but not PCT) level. Conversely, practice nurse supply was associated with lower admission rates at PCT level, but unfortunately these data are not readily available at practice level. These and similar findings, together

Table 3 Summary of estimated, observed and undiagnosed COPD prevalence and admission rates

\begin{tabular}{|c|c|c|c|c|c|c|c|c|c|}
\hline & \multirow[b]{2}{*}{ Mean } & \multicolumn{4}{|c|}{ PCT level } & \multicolumn{4}{|c|}{ Practice level } \\
\hline & & (SD) & Min-Max & Median & IQR & (SD) & Min-Max & Median & IOR \\
\hline Populations & 352286 & 193433 & $94635-1294596$ & 292118 & $225238-422895$ & 4011 & $984-38343$ & 5774 & $3394-9011$ \\
\hline Estimated prevalence & $3.8 \%$ & $0.9 \%$ & $2.1-6.0 \%$ & $3.6 \%$ & $3.1-4.4 \%$ & $1.1 \%$ & $0.7-7.5 \%$ & $3.6 \%$ & $2.9-4.6 \%$ \\
\hline Observed prevalence & $1.5 \%$ & $0.4 \%$ & $0.7-2.5 \%$ & $1.5 \%$ & $1.3-1.8 \%$ & $0.8 \%$ & $0.0-7.5 \%$ & $1.4 \%$ & $1.0-2.0 \%$ \\
\hline $\begin{array}{l}\text { Estimated/observed (undiagnosed) } \\
\text { prevalence }\end{array}$ & $2.2 \%$ & $0.9 \%$ & $0.6-4.3 \%$ & $2.0 \%$ & $1.5-3.0 \%$ & $1.0 \%$ & $-2.6-6.0 \%$ & $2.1 \%$ & $1.4-3.0 \%$ \\
\hline Estimated/observed prevalence ratio & 2.6 & 0.7 & $1.4-5.0$ & 2.4 & $2.0-3.0$ & 8.4 & $0.5-577.4$ & 2.5 & $1.9-3.5$ \\
\hline Undiagnosed/observed prevalence ratio & 1.6 & 0.7 & $0.4-4.0$ & 1.4 & $1.0-2.0$ & 8.4 & $-0.5-576.4$ & 1.5 & $0.9-2.5$ \\
\hline Admissions/100000 population* & 265.3 & 104.2 & $124.7-646.5$ & 241.5 & $178.1-331.4$ & 170.8 & $0.0-2175.2$ & 179.0 & $111.1-288.2$ \\
\hline
\end{tabular}

\footnotetext{
*Admission rates are directly standardised at PCT level and adjusted for age and sex (indirectly standardised) at practice level.
} 
Table 4 Multiple regression analyses

\begin{tabular}{lllr}
\hline PCT level* & $\begin{array}{l}\text { Regression } \\
\text { coefficient }\end{array}$ & 95\% Cls & p Value \\
\hline Observed prevalence & 1.325 & 1.204 to 1.459 & $<0.001$ \\
IMD (deprivation) score & 1.023 & 1.018 to 1.028 & $<0.001$ \\
GPs/100000 population & 0.995 & 0.991 to 1.000 & 0.052 \\
Practice nurses/100000 population & 0.992 & 0.987 to 0.996 & 0.001 \\
Smoking prevalence & 1.023 (Ed) & 1.012 to 1.033 & $<0.001$ \\
OOF PE7 & 0.678 & 0.466 to 0.985 & 0.042 \\
\hline & Incidence & & \\
Practice level† & rate ratio & $\mathbf{9 5 \%}$ Cls & p Value \\
\hline Observed prevalence & 1.224 & 1.206 to 1.243 & $<0.001$ \\
Undiagnosed prevalence & 1.045 & 1.032 to 1.059 & $<0.001$ \\
IMD (deprivation) score & 1.009 & 1.006 to 1.012 & $<0.001$ \\
Smoking prevalence & 1.036 & 1.031 to 1.042 & $<0.001$ \\
GPs/100000 population & 0.998 & 0.998 to 0.999 & $<0.001$ \\
OOF PE7 & 0.790 & 0.730 to 0.855 & $<0.001$ \\
OOF PE8 & 0.902 & 0.850 to 0.957 & 0.001 \\
COPD clinical quality 8 & 0.825 & 0.690 to 0.987 & 0.036 \\
(influenza immunisation) (Ed) & & & \\
\hline
\end{tabular}

${ }^{*}$ Stepwise linear regression. Adjusted R-squared $=0.75$. Dependent variable: admission rates for COPD.

†Stepwise Poisson regression, Dependent variable: observed admission count. COPD, chronic obstructive pulmonary disease; COPD 8, the percentage of patients with COPD who have had influenza immunisation in the preceding 1 September to 31 March; GP, general practitioner; IMD, Index of Multiple Deprivation; PCT, primary care trust; PE7, score for ability to obtain a consultation within two working days; PE8, score for ability to book an appointment with a GP more than 2 days ahead; QOF, Quality and Outcomes Framework.

with the impacts demonstrated in our QOF indicator analysis, highlight the need for adequate primary care provision in deprived areas. Geographical inequalities in GP supply have been persistent despite needs-based funding of PCTs. ${ }^{27}$

Our study was strengthened by using data from a national population, giving a high level of statistical power, and by combining practice-level data and estimates from a number of sources which were previously unavailable or only available locally. This revealed associations which may have been masked in previous studies which used the organisation as the level of analysis. This study is also the first to examine estimates of undiagnosed disease and its association with hospital admissions.

The BTS definition of COPD used for the prevalence estimates is stringent, which may lead to underestimation of the effect of undiagnosed disease prevalence. Conversely, the COPD model does not include lack of bronchodilator responsiveness in the definition of COPD, so this will slightly overestimate prevalence. We were able to include several new OOF clinical quality and patient experience indicators. Our analysis also illustrates the greater benefits of using practice level rather than organisation level data. Our findings would be strengthened by similar analyses of other long-term conditions, which would also validate the selection of PCS conditions, and assist in regulation of primary care.

There are several limitations. Hospital or general practice diagnostic coding may be incorrect. However, the advent of diagnosis-based payment of hospitals has accelerated improvement in data quality. We only considered primary or principal diagnosis, and $87.2 \%$ of primary diagnoses for hospital admissions in England are coded correctly. ${ }^{28}$ Counts of annual hospital admissions per practice were relatively low, even using means of 3 years' data (mean per year $=12.9$, median per year $=10.0$ ). We used appropriate methods (indirect standardisation and Poisson regression) to deal with this, and were reassured by the overall consistency between the results at organisation and practice levels. Furthermore, a number of UK agencies use practice-level admission data to support commissioning and quality improvement, so its use should prompt similar scrutiny to that which followed use of similar data at hospital level. In the case of COPD, general practices may add patients to COPD registers without necessary confirmatory spirometry-only $82.4 \%$ have a record of this test. This will overestimate the correctly diagnosed prevalence.

Reported practice populations may overestimate actual numbers, especially in urban areas with high mobility. Conversely, a small number of residents may not be registered with a practice. There is also a high level of achievement of many QOF indicators which results in a 'ceiling effect', which may reduce the ability to detect real differences in clinical quality. Many QOF indicators measure care processes which may not be strongly related to disease outcomes (as our analysis suggests). The impact of recent changes in quality of care on outcomes such as hospital admission may be delayed, but changes in QOF scores between 2005 and 2007 were small. Other data inevitably covered slightly different periods and dates. HES data do not include privately funded hospital admissions, but the vast majority of unplanned admissions for COPD are to NHS hospitals. We did not analyse readmissions separately as the focus was on factors affecting exacerbations in the community. Practice-level COPD and smoking prevalence estimates are based on the limited range of risk factor data available locally.

There are now several disease prevalence models for England which enable comparisons of QOF-registered and expected prevalence counts. We showed an association between admission rates and undiagnosed prevalence. The National COPD Audit has shown that $90 \%$ of those hospitalised with COPD were known to have the diagnosis before admission and to suffer exacerbations frequently. ${ }^{29}$ However, a population survey from Spain showed a high rate of undiagnosed COPD, and significant impairment in health-related quality of life and activities of daily living in undiagnosed individuals. ${ }^{30}$ Patients who have frequent exacerbations irrespective of disease severity may represent a distinct COPD phenotype, implying that earlier diagnosis and intervention may improve outcomes. ${ }^{31}$ The validity of the model, and the cost-effectiveness of targeted COPD case-finding strategies in practices with high estimates of undiagnosed disease, should therefore be evaluated.

The new QOF Patient Experience indicators were introduced, as their title suggests, to improve patient satisfaction with access to primary healthcare. However, the strong association between these indicators and admission rates suggests that they also reflect clinically important aspects of access. The National COPD Audit showed that $74 \%$ of admitted patients make contact with their general practice in the month before admission and $31 \%$ have three or more contacts in those 4 weeks. ${ }^{29}$ Given that the ability to access primary care rapidly during a COPD exacerbation may well reduce admission risks, the association with PE7, the ease of obtaining a consultation, is plausible. That there is also an association with PE8, the ease of making non-urgent appointments, and with GPs per 100000 practice population, suggests that access barriers may also affect ongoing COPD management.

At practice level, only QOF COPD indicator 8, uptake of influenza immunisation, was associated with hospital admission rates. This is clinically plausible. The other QOF COPD indicators are measures of clinical processes and standards which are less likely to affect outcomes. Alternatives which are more likely to affect outcomes should be considered. For example, practices could be incentivised to deliver more intensive smoking cessation services to COPD patients. The updated NICE COPD guidelines currently out for consultation recommend that 
pulmonary rehabilitation should be made available to all appropriate patients with COPD, and that newer long-acting drugs be prescribed to appropriate patients. ${ }^{32}$ The interventions in the Chronic Care Model reduce admission rates, although they are difficult to measure. ${ }^{21}$ Finally, other factors which could affect admission rates include the quality of out of hours services, the presence of specialist nurse services, and the supply and quality of hospital services.

Acknowledgements We thank the Care Quality Commission and the NHS Information Centre for supplying some of the data used in this study. Imperial College London is grateful for the support from the National Institute for Health Research Biomedical Research Centre Scheme, the National Institute for Health Research Collaboration for Leadership in Applied Health Research and Care Scheme, and the Imperial Centre for Patient Safety and Service Quality.

Funding This study was supported by the Department of Public Health \& Primary Care at Imperial College London. The Dr Foster Unit at Imperial College London is funded by Dr Foster Intelligence. AC is funded by a Grant for Spanish Professionals' Training Abroad (MAPFRE foundation, 2009) and the XXI European Programme for Research Fellowships (Caja Inmaculada grant-making foundation, 2009). LC is funded by the London Deanery. MS is funded by the Economic \& Social Research Council. AB is funded by Dr Foster Intelligence. GA was an employee of the Care Quality Commission. The views expressed in the article are those of the authors.

Competing interests None.

Contributors MS and $A M$ conceived and planned the study. $A C$ and $A B$ undertook the statistical analysis and all authors were involved in the interpretation of the data. LC wrote the first draft of the paper. All authors revised it critically for important intellectual content and approved the final version.

Provenance and peer review Not commissioned; externally peer reviewed.

\section{REFERENCES}

1. World Health Organisation. Chronic obstructive pulmonary disease (COPD): key facts. 2010; Fact sheet no 315. http://www.who.int/mediacentre/factsheets/fs315/ en/index.html (accessed 20 Jan 2010).

2. World Health Organisation. COPD Burden. World Health Organisation, 2010. http://www.who.int/respiratory/copd/burden/en (accessed 20 Jan 2010).

3. Pride N. Chronic obstructive pulmonary disease in the United Kingdom: trends in mortality, morbidity, and smoking. Curr Opin Pulm Med 2002;8:95-101.

4. Healthcare Commission. Clearing the Air: A National Study of Chronic Obstructive Pulmonary Disease. Commission for Healthcare Audit and Inspection, 2006. http:// www.cqc.org.uk/ db/ documents/COPD factsheet.pdf (accessed 20 Jan 2010).

5. Department of Health. Development of the COPD National Service Framework. 2009. http://www.dh.gov.uk/en/Healthcare/NationalServiceFrameworks/COPD/ DH 085153 (accessed 13 May 2009).

6. Information Centre for Health \& Social Care. The quality \& outcomes framework. 2009. http://www.ic.nhs.uk/statistics-and-data-collections/audits-and-performance/ the-quality-and-outcomes-framework (accessed 20 Jan 2010).

7. Nacul L, Soljak M, Meade T. Model for estimating the population prevalence of chronic obstructive pulmonary disease: cross sectional data from the Health Survey for England. Popul Health Metr 2007;5:8.

8. HM Treasury. Pre-Budget Report 2009: Securing the recovery: growth and opportunity. 2009. http://www.hm-treasury.gov.uk/prebud_pbr09_repindex.htm (accessed 20 Jan 2010).

9. Health Intelligence Unit. Victorian Ambulatory Care Sensitive Conditions Study. Department of Health, State Government of Victoria, Australia, 2009. http://www. health.vic.gov.au/healthstatus/downloads/prelimanalyses.pdf (accessed 20 Jan 2010)

10. NHS Institute for Improvement \& Innovation. NHS better care, better value indicators: clinical productivity- managing variation in emergency admissions. 2010.
http://www.productivity.nhs.uk/Def ManagingVariationlnEmergencyAdmissions.aspx (accessed 20 Jan 2010)

11. Prevention Quality Indicators Composite Measure Workgroup. Guide to Prevention Quality Indicators: Hospital Admission for Ambulatory Care Sensitive Conditions. Agency for Healthcare Research and Quality, 2006. http://www. qualityindicators.ahrq.gov/downloads/pqi/pqi guide v31.pdf (accessed 20 Jan 2010).

12. Purdy S, Griffin T, Salisbury C, et al. Prioritizing ambulatory care sensitive hospital admissions in England for research and intervention: a Delphi exercise. Prim Health Care Res Dev 2010:11:41-50

13. Sanderson C, Dixon J. Conditions for which onset or hospital admission is potentially preventable by timely and effective ambulatory care. J Health Serv Res Policy 2000:5:222-30.

14. Ansari Z, Laditka JN, Laditka SB. Access to health care and hospitalization for ambulatory care sensitive conditions. Med Care Res Rev 2006:63:719-41.

15. Basu J, Mobley LR. Do HMOs reduce preventable hospitalizations for Medicare beneficiaries? Med Care Res Rev 2007;64:544-67.

16. Griffiths C, Sturdy P, Naish J, et al. Hospital admissions for asthma in east London: associations with characteristics of local general practices, prescribing, and population. BMJ 1997; 314:482

17. Saxena S, George J, Barber J, et al. Association of population and practice factors with potentially avoidable admission rates for chronic diseases in London: cross sectional analysis. J R Soc Med 2006;99:81-9.

18. Godtfredsen NS, Vestbo J, Osler M, et al. Risk of hospital admission for COPD following smoking cessation and reduction: a Danish population study. Thorax 2002:57:967-72.

19. Calverley PM, Anderson JA, Celli B, et al. Salmeterol and fluticasone propionate and survival in chronic obstructive pulmonary disease. N Engl J Med 2007:356:775-89.

20. Sutherland ER, Allmers H, Ayas NT, et al. Inhaled corticosteroids reduce the progression of airflow limitation in chronic obstructive pulmonary disease: a meta-analysis. Thorax 2003:58:937-41.

21. Adams SG, Smith PK, Allan PF, et al. Systematic review of the chronic care model in chronic obstructive pulmonary disease prevention and management. Arch Intern Med 2007:167:551-61.

22. Information Centre for Health \& Social Care. NHS Staff 1997-2007 (General Practice). 2008. http://www.ic.nhs.uk/cmsincludes/ process document.asp? sPublicationID=1205322211194\&sDoclD=4100 (accessed 25 Mar 2010).

23. Association of Public Health Observatories. Browsing disease prevalence models. 2009. http://www.apho.org.uk/resource/view.aspx?RID=48308 (accessed 2 Dec 2009)

24. Department of Communities \& Local Government. The English Indices of Deprivation 2004 (revised). Department for Communities \& Local Government, 2008. http://www.communities.gov.uk/publications/communities/englishindices laccessed 8 Jul 2008).

25. Majeed A, Bardsley M, Morgan D, et al. Cross sectional study of primary care groups in London: association of measures of socioeconomic and health status with hospital admission rates. BMJ 2000;321:1057-60.

26. Reid FDA, Cook DG, Majeed A. Explaining variation in hospital admission rates between general practices: cross sectional study. BMJ 1999;319:98-103.

27. Goddard M, Gravelle H, Hole A, et al. Where did all the GPs go? Increasing supply and geographical equity in England and Scotland. J Health Serv Res Policy 2010;15:28-35.

28. Audit Commission. PbR data assurance framework. 2009. http://www.auditcommission.gov.uk/SiteCollectionDocuments/AuditCommissionReports/ NationalStudies/20090827pbrdataassuranceframework0809rep.pdf laccessed 3 May 2010).

29. Clinical Effectiveness and Evaluation Unit. National COPD audit 2008. The Royal College of Physicians, 2010. http://www.rcplondon.ac.uk/clinical-standards/ceeu/ Current-work/ncrop/Pages/auditaspx (accessed 28 Jan 2010).

30. Miravitlles M, Soriano JB, Garcia-Rio F, et al. Prevalence of COPD in Spain: impact of undiagnosed COPD on quality of life and daily life activities. Thorax 2009;64:863-8.

31. Hurst JR, Vestbo J, Anzueto $\mathrm{A}$, et al. Susceptibility to exacerbation in chronic obstructive pulmonary disease. N Engl J Med 2010;363:1128-38.

32. National Institute for Clinical Excellence. CG101 Chronic obstructive pulmonary disease (update): full guideline. National Institute for Clinical Excellence website, 2010 http://guidance.nice.org.uk/CG101/Guidance/pdf/English (accessed 23 Sep 2010). 


\section{Correction}

Calderón-Larrañaga A, Carney L, Soljak M, et al. Association of population and primary healthcare factors with hospital admission rates for chronic obstructive pulmonary disease in England: national cross-sectional study. Thorax 2011;66:191-96.

We wish to report a single error in our paper on associations of population and primary healthcare factors with hospital admission rates for chronic obstructive pulmonary disease. An observant researcher has questioned an $\mathrm{R}$ squared value for a univariate analysis at primary care trust level. In our paper we reported that about $14.4 \%$ of the variance in hospital admissions was explained by GP supply. We have re-run the analyses and confirm that there was a typographical error on our part. The $\mathrm{R}$ squared value of $14.4 \%$ was actually for the variable GP list size and not for GP supply (the latter has a R squared of $0.1 \%$ ). The rest of the values are correct. We consider that this correction has no effect on the overall conclusions of our paper, as the important findings were at general practice level.

Thorax 2013;68:781. doi:10.1136/thx.2010.147058corr1 